\title{
Optimizing Medical Enterprise's Operations Management considering Corporate Social Responsibility under Industry 5.0
}

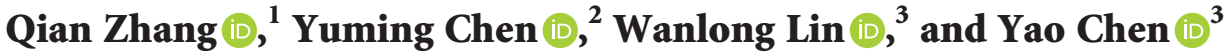 \\ ${ }^{1}$ School of Management, Shanghai University, 99 Shangda Road, Baoshan District, Shanghai 200444, China \\ ${ }^{2}$ Shanghai Jing'an Mental Health Center, 80 PingYao Road, Jing'an District, Shanghai 200040, China \\ ${ }^{3}$ Shanghai No. 3 Rehabilitation Hospital, 100 JiaoCheng Road, Jing'an District, Shanghai 200072, China
}

Correspondence should be addressed to Yao Chen; 1995jiangpyn@163.com

Received 23 August 2021; Revised 16 October 2021; Accepted 27 October 2021; Published 27 November 2021

Academic Editor: Tingsong Wang

Copyright (c) 2021 Qian Zhang et al. This is an open access article distributed under the Creative Commons Attribution License, which permits unrestricted use, distribution, and reproduction in any medium, provided the original work is properly cited.

Corporate social responsibility (CSR) is the concrete practice of sustainable development at the enterprise level, emphasizing the human value in the production process. The proposal of Industry 5.0 begins to take the coordinated development between human and various production factors as one of the key points of corporate sustainable management. Therefore, this paper studies the optimization of medical enterprise's operations management considering enterprise CSR under Industry 5.0. A mixed-integer programming (MIP) model is developed to maximize the CSR with the consideration of the impact of precision medical technologies such as surgical robots (SRs) and 3D bone printing on employee social welfare, corporate profits, social environment, and customer surplus value. An improved variable neighborhood tabu search (IVNTS) algorithm which combines the variable neighborhood tabu search (VNTS) algorithm and simulated annealing (SA) algorithm is designed to solve the model, and numerical experiments are analyzed to verify the effectiveness of the proposed IVNTS. The research aids medical enterprise to make reasonable operations management decisions, while providing a reference for the government to draft and implement related policies, thereby achieving sustainable social development.

\section{Introduction}

It has been more than 240 years since the first industrial revolution was proposed in 1780, which has gone through four stages of mechanization, electrification, automation, and digitalization. The emergence of intelligence and interconnection signifies that the manufacturing industry has entered an era of technology reform [1]. The promulgation and implementation of the "New Generation Artificial Intelligence Development Plan," "EU Civil Law Rules on Robotics," accelerates the global integration of cutting-edge technology and traditional industries, and the fifth industrial revolution (Industry 5.0) comes into being. Industry 5.0 focuses on human-machine collaboration, bringing humans back to industrial production through the utilization of emerging technologies such as collaborative robots, additive manufacturing (3D printing), Internet of Things, virtual and physical integration, material engineering, and artificial intelligence (AI). In addition, mass customization is realized based on the integration of personal characteristics and the accuracy of emerging technologies in the manufacturing process, and personnel's cognitive and thinking skills can provide value-added personalized services, thereby achieving close collaboration between machines and humans [2].

Industry 5.0 supports the sustainable development of enterprises through the rational utilization of emerging technologies. Industry 5.0 is committed to coordinating the relationship between humans and machines. Humans would be brought back into the production process by employing cooperative robots, thus resulting in increased human value via better human-machine cooperation. Reduced waste, better resource utilization, and insurance of high product 
quality can be accessed by improving the productivity of enterprises. Meanwhile, with improved customer and employee satisfaction, the sustainable development of enterprises encounters great promotion.

The outbreak of the coronavirus disease 2019 (COVID19) has accelerated the development of healthcare. Enhanced surgical robots (SRs), 3D bone printing, 5G, big data, cloud interconnection, and other personalized, refined, and remote emerging technologies are used in medical care. The all-round applications of those technologies in the medical field are particularly important. SRs can effectively replace medical staff in cleaning and disinfecting wards, measuring body temperature, delivering medicine, and other remote zero-contact care services for patients. 3D bone printing technology has greatly improved the efficiency and accuracy of surgical operations and provides customers with personalized medical care solutions. The application of 5G, big data, and cloud interconnection technology can provide electronic health records and achieve information sharing among multiple medical institutions, thereby providing services such as accurate bed allocation and remote expert consultation.

In the 1880 s, the corporate social responsibility (CSR) campaign gradually emerged in developed countries in Europe and the United States, and companies were required to fulfill certain social responsibilities while trading. Sustainable supply chain has become the cornerstone for enterprises to achieve sustainable goals [3]. CSR is embodied in the protection of resources and environment, the provision of high-quality products and services, the offers of more employment opportunities, the promotion of scientific and technological progress, and so forth. Furthermore, the attention to human value in the production process is emphasized. With the continuous improvement of people's demands for medical service level and under the pressure of competition and self-development requirements, the benefits balance problem of participants in the global sustainable supply chain needs to be solved urgently by medical companies. Consequently, they can better assume the global corporate social responsibility (GCSR).

Based on the above background, under Industry 5.0, this paper studies an optimization problem of operation management for medical enterprises considering social responsibility. A mixed-integer programming (MIP) model with the maximization of CSR is established as the objective function. An improved variable neighborhood tabu search (IVNTS) algorithm is proposed to efficiently solve the optimization model. The results of numerical experiments provide decision-making reference for the daily operations of the government and enterprises.

The main contributions are summarized as follows: (1) developing a quantitative analysis model with the goal of maximizing CSR, which is more practical than previous theoretical research; (2) designing an efficient improved variable neighborhood tabu search algorithm, which can obtain a satisfactory solution efficiently; (3) conducting a large number of numerical experiments, which provide management enlightenment for the operation and decisionmaking of medical enterprises.

\section{Literature Review}

A variety of personalized requirements promote the exploration and integration of emerging technologies derived from Industry 5.0 and enterprise operation management. Özdemir and Hekim [4] proposed that Industry 5.0 was to build a complex hyperlinked digital network without damaging the long-term sustainability of innovation ecosystems. Sung et al. [5] proposed that the combination of AI and healthcare will lead to tremendous changes in society. Mehmood [6] presented that the arrival of Industry 5.0 was imminent; thus coordinating AI and human intellect was inevitable. Rai and Rai [7] discussed that the application of nanotechnology in different industries affected the revolution in Industry 5.0. Sachsenmeier [8] considered that Industry 4.0 explored the future relationship between humans and machines, while Industry 5.0 involved the essence of human existence, personal safety, and its relationship with nature. Industry 4.0 focuses on automation, while Industry 5.0 focuses on the collaboration between humans and machines, which will provide more employment opportunities. The application of AI in the work process achieves a win-win situation. On the one hand, it uses human intellect and creativity to improve process efficiency. On the other hand, it realizes the sustainability of human civilization by reducing pollution and waste generation [9]. Therefore, companies must not only consider gaining benefits but also take the corresponding CSR into account.

This research only considers papers published in the Web of Science database in English language over the past decade, using "corporate social responsibility" as the search key, and the document types are limited to "article" and "review"; 20621 articles were returned. Figure 1 describes the time period distribution of published articles in this field of CSR. The increasing trend reflects the recognition of scholars on the importance of the field. Totally 20621 papers on the topic were published in more than 3,600 journals. Table 1 shows the top 10 journals with most published articles on the topic of CSR.

With the growth of human's prosocial preference and the increasing demand of sustainable development, scholar's attention and research on CSR have gradually increased, and the number of published papers also showed an obvious upward trend over the past decade [10]. With the in-depth promotion of concepts such as the circular economy and sustainable development, scholars have gradually begun to pay attention to the impact of CSR on the medical enterprise's operations management. It is an attempt to use the emerging technologies brought by Industry 5.0 to enable medical enterprises to achieve breakthrough innovations in operating modes, business modes, and manufacturing modes. Manikas et al. [11] proposed that it is very important to study CSR in the field of operations management. With the spread of the Internet on a global scale, most studies focus on global procurement and supply chain.

Research on CSR in operations management mostly considers corporate profits, product quality, employee welfare, environmental protection, and so forth. Research in developing countries mostly focuses on improving social 


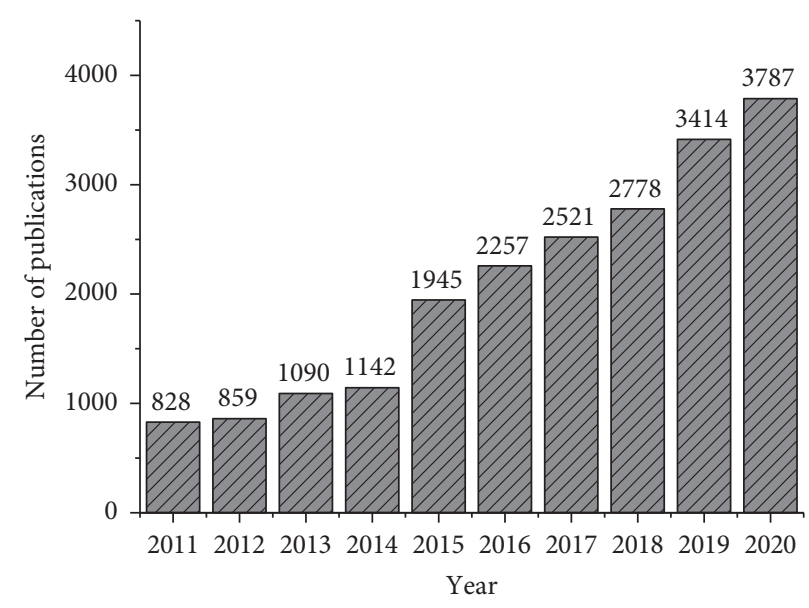

FIgURE 1: Publication trend of CSR in the recent decade.

TABLE 1: Top ten journals in terms of number of publications on CSR.

\begin{tabular}{lc}
\hline Journal name & Total number \\
\hline Journal of Business Ethics & 1137 \\
Sustainability & 1037 \\
Journal of Cleaner Production & 840 \\
Corporate Social Responsibility and Environmental Management & 633 \\
Business Strategy and the Environment & 359 \\
Social Responsibility Journal & 306 \\
Journal of Business Research & 237 \\
Business Society & 206 \\
Corporate Governance: The International Journal of Business in Society & 195 \\
Business Ethics: A European review & 161 \\
\hline
\end{tabular}

welfare and labor rights protection; meanwhile, in developed countries, scholars pay more attention to environment protection and resource utilization. Feng et al. [12] revealed that most studies focused on sustainable development and economic and social effects, while there was a lack of practical and normative modeling research in their review of CSR of supply chain management. Some scholars have conducted research on the basic theory, as well as the importance and application of CSR. Afsar et al. [13] proposed that CSR can have a positive impact on the proenvironmental behaviors of employers and suggested that the CSR should be included in sustainable development strategies. Mark [14] believed that enterprises can benefit from social responsibility. Zhu and Lai [15] performed an analysis and found that multinational companies can improve their supply chain operations by expanding the practice of CSR from the perspective of capital. Koo and $\mathrm{Ki}$ [16] believed that employees are an important part of the company's sustainable development, and they also analyzed the impact of CSR investment on employee safety. Kurucz et al. [17] proposed that CSR is conducive to reducing corporate costs and risks, enhancing legitimacy and reputation, and establishing corporate competitive advantages. Babor and Robaina [18] discussed the relationship among the alcohol industry, academic medicine, and the public health community based on CSR. Daú et al. [19] analyzed the relationship between CSR and sustainable practice in healthcare institutions, and they proposed a conceptual framework of circular economy transformation with the CSR mirror. Lee and Tang [20] proposed that, in analyzing the value chain of CSR, new constraints, multiple goals, and multiple stakeholders are involved. Therefore, existing operations management research cannot be simply expanded or modified to solve this problem. Ngai et al. [21] conducted a case analysis of three companies and found that CSR could bring high-quality products and services, reliable and efficient supply chains, stable cash flow, loyal customer base, and good social image. Cruz and Matsypura [22] established a CSR-based mathematical modeling of the supply chain network with the goal of maximizing net profit and minimizing waste emissions and risks on the basis of considering environmental factors. Cruz [23] analyzed the impact of supply-side interruption risk, social risk, and demand uncertainty and established a decision-making model based on CSR and global supply chain, with the goal of maximizing profit and minimizing risk. Liu [24] proposed a new hybrid multiattribute decision model to evaluate the impact of the implementation of internal control including CSR.

In summary, companies can create benefits by considering CSR when formulating corporate strategies. The application of emerging technologies derived from Industry 5.0 will aid companies to improve their service levels and enhance their competitiveness. The modeling and analysis of CSR in the previous literature mostly took CSR 
as one of the consideration factors and pursued the maximization of corporate profits, rather than taking CSR maximization as one of the corporate goals. To solve the proposed problem, this paper proposes the optimization problem of operation management considering CSR based on the research of Industry 5.0 and CSR and develops an MIP model with the goal of maximizing CSR. An IVNTS algorithm is designed to solve the model. Numerical experiments are conducted to verify the effectiveness and efficiency of the algorithm.

\section{Problem Description}

With the advent of the era of medical and health consumption, people have put forward higher requirements on the quality of medical and health products and the reputation of enterprises. To enhance the core competitiveness of enterprises, medical companies not only need to ensure product quality but also fulfill CSR.

In the global supply chain environment, the sales, procurement, and supply systems of multinational medical companies have formed a global supply pattern. This paper constructs a global supply chain sales and operation network based on SRs, including domestic and foreign suppliers, and sales market is shown in Figure 2.

SRs are new type of medical devices integrating medicine, mechanics, biomechanics, and other disciplines, which can be applied in many fields such as joint replacement and fracture reduction. SRs produced by an enterprise will be sold in market $i$. In order to produce SRs, the enterprise needs to purchase from supplier $j$. The emergence of SRs has greatly promoted the development of minimally invasive and intelligent surgical operations, and the existing special features effectively overcome the problems of poor accuracy, excessive operation time, and doctor fatigue in traditional surgical operations. A large number of consumers believe that the assistance of SRs makes surgery more efficient and accurate. SRs manufactured abroad perform better in product quality $q_{j}$ than domestic ones. Therefore, SRs produced by foreign manufacturers can be set a higher price $p_{i, j}$ in the market [25].

The development of technology has improved the production level of foreign suppliers, their lead time $l_{i, j}$ will be shortened, and operating costs $c_{j, t}$ (including material costs, labor costs, equipment costs, etc.) will be reduced. Set the technical learning coefficient as $\theta^{K}$; then $c_{j, t+1}=c_{j t} \theta^{K}$. Operating costs are easy to measure, and, consequently, they are widely used in sustainable supply chain optimization research [26]. The utilization of SRs will increase not only social welfare but also the worker's income $w_{j}$ corresponding to unit production capacity and the surplus value $v_{i, j}$ for hospital. The transportation and environmental cost $e_{i, j}$ is determined by the unit transportation cost of the products, the transportation distance, and the environmental pollution cost caused during transportation. For multinational medical enterprises, the primary decision is to determine capacity $x_{j}$ that supplier $j$ can provide and the sales price $p_{i, j}$ of the SR provided by supplier $j$ in market $i$ to maximize CSR.
Once the primary decision is determined, the actual supply $y_{i, j, r, t}$ provided by supplier $j$ to the sales market $i$ during the $t$ period under the scenario $r$ should be considered, which is related to the market demand $d_{i, j, r, t}$. The market demand $d_{i, j, r, t}$ of SRs is affected by random number $\varepsilon_{i, j, r, t}$, price $p_{i, j}$, quality $q_{j}$, and lead time for delivery $l_{i, j}$. When the suppliers and the markets are in the same area, the random number $\varepsilon_{i, j, r, t}$ obeys the distribution $N\left(\mu_{i, j}, \sigma_{i, j}\right)$. When the suppliers and the markets are in different area, the market demand is to some extent influenced by $\mu_{i, j}$ and $\sigma_{i, j}$, set $\theta^{D}$ as the demand learning coefficient, and then $\varepsilon_{i, j, r, t}$ obeys the distribution $N\left(\mu_{i, j+1}, \theta^{D} \cdot \sigma_{i, j} \cdot \mu_{i, j+1} / \mu_{i, j}\right)$.

\section{Mathematical Model}

Based on the previous studies, an MIP model is constructed to maximize the medical CSR. Different scenarios are considered to meet the uncertain demand in reality. In addition, product requirements and the actual supply vary in different scenarios.

\subsection{Notation}

4.1.1. Indices and Sets. I: the set of sales market types; $I=\{1,2\}$, indexed by $i$, where 1 indicates domestic sales market and 2 indicates foreign sales market;

$J$ : the set of supplier types; $J=\{1,2\}$, indexed by $j$, where 1 indicates domestic suppliers and 2 indicates foreign suppliers;

$R$ : the set of scenarios; $R=\{1,2, \ldots, r, \ldots,|R|\}$, indexed by $r$;

$T$ : the set of time-steps; $T=\{1,2, \ldots, t, \ldots,|T|\}$, indexed by $t$.

4.1.2. Parameters. $e_{i, j}$ : the unit cost of transportation and environmental for transporting SR by supplier $j$ to sales market $i$.

$v_{i, j}$ : the surplus value for selling per unit product provided by supplier $j$ to the sales market $i$.

$w_{j}$ : the income of workers corresponding to the unit production capacity provided by supplier $j$.

$c_{j, t}$ : the unit operating cost of supplier $j$ during time-step $t$.

$d_{i, j, r, t}:$ the product demand of sales market $i$ for suppliers $j$ in the scenario $r$ during time-step $t$.

$\alpha$ : quantity conversion coefficient; the quality of products produced by supplier $j$ in the demand function is expressed in quantity.

$\beta$ : quantity conversion coefficient; the product price provided by supplier $j$ to the sales market $i$ in the demand function is expressed in quantity.

$\gamma$ : quantity conversion efficient; the supply lead time from supplier $j$ to the sales market $i$ in the demand function is expressed in quantity.

$q_{j}$ : the quality of the product produced by supplier $j ; q_{j}^{s}$ represents its standardized value; $q_{j}^{s}=q_{j}-q_{j}^{\min } / q_{j}^{\max }-q_{j}^{\min }$. 


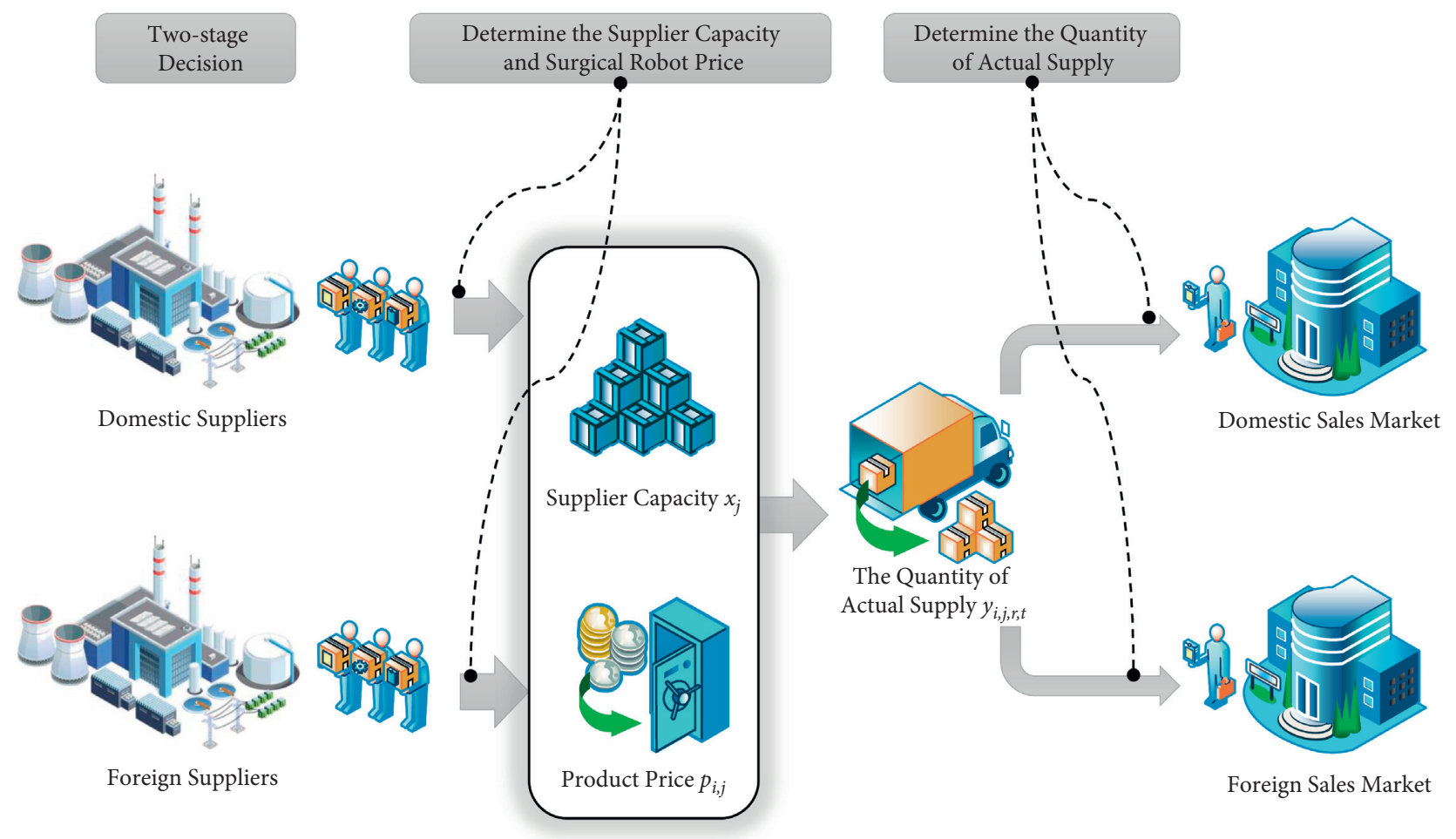

FIgURE 2: Global supply chain sales and operation network.

$l_{i, j}$ : the delivery lead time of supplier $j$ to the sales market $i ; l_{i, j}^{s}$ represents its standardized value; $l_{i, j}^{s}=l_{i, j}^{\max }-$ $l_{i, j} / l_{i, j}^{\max }-l_{i, j}^{\min }$.

4.1.3. Decision Variables. $x_{j}$ : the product capacity provided by supplier $j$.

$p_{i, j}$ : the price of the product provided by supplier $j$ in sales market $i$.

$p_{i, j}^{s}$ : the price standardized value of the product provided by supplier $j$ to sales market $i$.

$y_{i, j, r, t}:$ the quantity of actual supply provided by supplier $j$ to sales market $i$ under scenario $r$ during $t$ time-step.

\subsection{Mathematical Model.}

$\mathrm{CSR}=\max \sum_{j \in J} w_{j} \cdot x_{j}+\frac{1}{R} \sum_{i \in I} \sum_{j \in J} \sum_{r \in R} \sum_{t \in T} y_{i, j, r, t} \cdot\left[p_{i, j}-c_{j, t}-e_{i, j}+v_{i, j}\right]$.

It is subject to

$$
\begin{aligned}
p_{i, j}^{s} & =\frac{p_{i, j}-p_{i, j}^{\min }}{p_{i, j}^{\max }-p_{i, j}^{\min }}, \quad \forall i \in I, \forall j \in J, \\
d_{i, j, r, t} & =\varepsilon_{i, j, r, t}+\alpha \cdot q_{j}^{s}-\beta \cdot p_{i, j}^{s}-\gamma \cdot l_{i, j}^{s}, \quad \forall i \in I, \forall j \in J, \forall r \in R, \forall t \in T,
\end{aligned}
$$

$$
y_{i, j, r, t} \leq d_{i, j, r, t}, \quad \forall i \in I, \forall j \in J, \forall r \in R, \forall t \in T,
$$

$$
\begin{aligned}
x_{j} & \geq \sum_{i \in I} y_{i, j, r, t}, \quad \forall j \in J, \forall r \in R, \forall t \in T, \\
\sum_{j \in J} x_{j} & \leq \sum_{i \in I} \sum_{j \in J} d_{i, j, r, t}, \quad \forall r \in R, \forall t \in T, \\
x_{j} & \geq 0, \quad \forall j \in J, \\
p_{i, j} & \geq 0, \quad \forall i \in I, \forall j \in J, \\
y_{i, j, r, t} & \geq 0, \quad \forall i \in I, \forall j \in J, \forall r \in R, \forall t \in T .
\end{aligned}
$$

The objective function (1) aims to maximize the CSR. The first term represents the social welfare of employees brought by medical enterprises. The second term represents the sum of the profit, environmental impact, and surplus value generated by the operation of a medical enterprise under any scenario and uncertain demand. Constraint (2) is to standardize the product price $p_{i, j}$. Constraint (3) is the demand function of the product. Product demand is affected by product price $p_{i, j}^{s}$, product quality $q_{j}^{s}$, and delivery lead time $l_{i, j}^{s} \cdot \varepsilon_{i, j, r, t}$ is a random number that obeys the normal distribution $N\left(\mu_{i j}, \sigma_{i j}\right)$. Constraint (4) indicates that the quantity of actual supply of the product should be less than the total demand for it. Constraint (5) states that the sum of the quantities of supplier $j$ 's actual supply cannot exceed the capacity of supplier $j$. Constraint (6) expresses that, considering the particularity of SRs, the capacity of supplier $j$ is less than the total demand for this supplier in each market. Constraints (7)-(9) define the domains of decision variables. 
4.3. Linearization. Since $y_{i, j, r, t} \cdot p_{i, j}$ in the second term of the objective function is nonlinear, this paper defines new continuous variables $\theta_{i, j, r, t, h}$ and the binary variable $y_{i, j, r, t, h}$ to linearize it, and relevant constraints (11)-(17) are expressed as follows.

4.3.1. Added Variables. $y_{i, j, r, t, h}$ : equal to 1 if the quantity of actual supply is $h$ which supplier $j$ provides to the sales market $i$ under scenario $r$ during time-step $t$ and 0 otherwise.

$\theta_{i, j, r, t, h}$ the product price when the quantity of actual supply is $h$ provided by supplier $j$ to the sales market $i$ under scenario $r$ during time-step $t$.

\subsubsection{The Objective Function after Linearization.}

$$
\mathrm{CSR}=\max \sum_{j \in J} w_{j} \cdot x_{j}+\frac{1}{R} \cdot \sum_{i \in I} \sum_{j \in J} \sum_{r \in R} \sum_{t \in T} \sum_{h \in H} h \cdot \theta_{i, j, r, t, h}+\frac{1}{R} \cdot \sum_{i \in I} \sum_{j \in J} \sum_{r \in R} \sum_{t \in T}\left(-c_{j, t}-e_{i, j}+v_{i, j}\right) \cdot y_{i, j, r, t} .
$$

\subsubsection{Added Constraints}

$$
\begin{gathered}
\sum_{h \in H} y_{i, j, r, t, h}=1, \quad \forall i \in I, \forall j \in J, \forall r \in R, \forall t \in T, \\
\sum_{h \in H} h \cdot y_{i, j, r, t, h}=y_{i, j, r, t}, \quad \forall i \in I, \forall j \in J, \forall r \in R, \forall t \in T, \\
\theta_{i, j, r, t, h} \leq p_{i, j}, \quad \forall i \in I, \forall j \in J, \forall r \in R, \forall t \in T, \forall h \in H, \\
\theta_{i, j, r, t, h} \leq M \cdot y_{i, j, r, t, h}, \quad \forall i \in I, \forall j \in J, \forall r \in R, \forall t \in T, \forall h \in H, \\
\theta_{i, j, r, t, h} \geq p_{i, j}-M \cdot\left(1-y_{i, j, r, t, h}\right), \quad \forall i \in I, \forall j \in J, \forall r \in R, \forall t \in T, \forall h \in H, \\
y_{i, j, r, t, h} \in\{0,1\}, \quad \forall i \in I, \forall j \in J, \forall r \in R, \forall t \in T, \forall h \in H, \\
\theta_{i, j, r, t, h} \geq 0, \quad \forall i \in I, \forall j \in J, \forall r \in R, \forall t \in T, \forall h \in H .
\end{gathered}
$$

\section{Improved Variable Neighborhood Tabu Search Algorithm}

Traditional commercial solvers (such as CPLEX) fail to solve large-scale problems in a short time. Therefore, this paper proposed a heuristic algorithm, improved variable neighborhood tabu search, to solve the proposed problem. VNS combines local search and variable neighborhood structure strategies, using various neighborhood structures to perform alternate searches [27-29]. The Tabu Search (TS) algorithm sets the tabu list and the tabu object according to the tabu criterion and avoids the repetition of extra operations in the next iterative search by marking the searched local optimal solution, thereby effectively reducing the search time [30]. Simulated annealing (SA) is a probability-based algorithm that can deal with nonlinear, discontinuous, and random objective functions and can effectively avoid falling into local optimum. We combine the cooling process of SA with tabu criteria and variable neighborhood search (VNS) to design an IVNTS algorithm. The alternate search of multiple neighborhood structures can increase the search depth, and the utilization of tabu list criteria and SA acceptance criteria prevents falling into local optima, thereby improving the solution quality of the proposed algorithm [31, 32]. The flow chart of IVNTS is shown in Figure 3.

5.1. Initial Solution Generation. The initial solution directly affects the quality of the metaheuristic algorithm solution. Thus, its necessary to generate high-quality initial solutions utilizing valid rules. The steps for generating the initial solutions in this paper are as follows.

Step 1: set $p_{i, j}$ as $\left(d_{i, j, r, t}-\varepsilon_{i, j, r, t}+\alpha \cdot q_{j, s}-\gamma \cdot l_{i, j, s} /-\beta\right)$. $\left(p_{i, j}^{\max }-p_{i, j}^{\min }\right)+p_{i, j}^{\min }$ to meet constraint (2) and (3).

Step 2: assign $x_{j}$ a value that satisfies constraint (6) based on $\min _{\forall r \in R, \forall t \in T}\left\{\sum_{i \in I} d_{i, j, r, t}\right\}$.

Step 3: set $y_{i, j, r, t}$ as $x_{j} / \sum_{i \in I} d_{i, j, r, t}$ to meet constraint (5); if the value of $y_{i, j, r, t}$ exceeds $d_{i, j, r, t}$ after assignment, set $y_{i, j, r, t}$ as $d_{i, j, r, t}$ to meet constraint (4).

5.2. Variable Neighborhood Search Strategy. In the iterative process of IVNTS, the local optimum of each neighborhood approximates the global optimum by changing the 


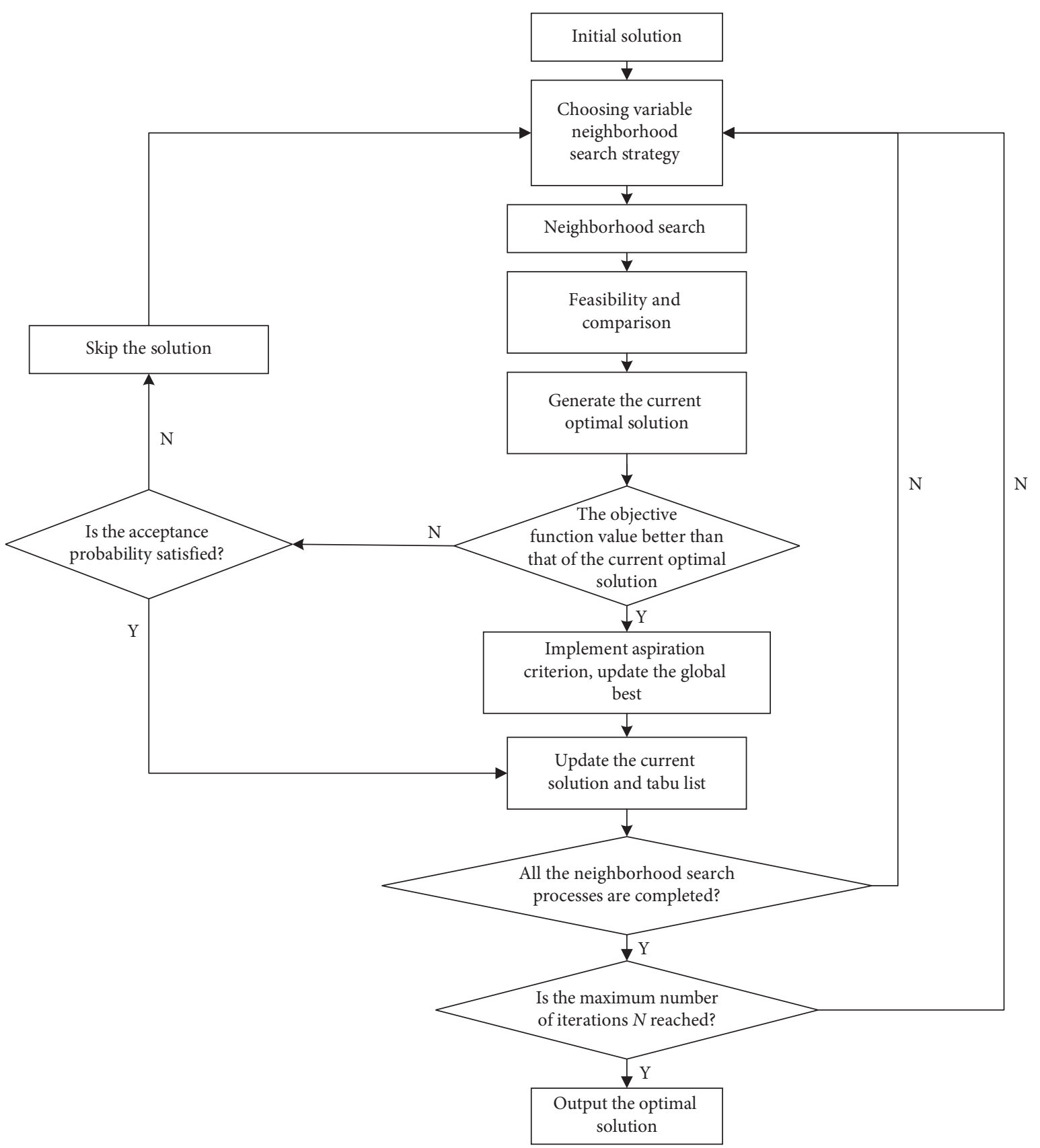

FIGURE 3: Flow chart of IVNTS algorithm.

neighborhood structure. Considering that the decision variables set in this paper are integer types, the two following neighborhood structures, $n$-flip and $n$-shift, are designed to participate in the iterative process of the algorithm.

5.2.1. N-Flip Search Strategy. The neighborhood search strategy mainly considers the decision variables $x_{j}$ and $y_{i, j, r, t}$. First, set one of the decision variables as $a$, $a=a \pm n(n \in\{1,2,3,0.1 a, 0.2 a, 0.5 a\})$, and then make the obtained solution feasible. Second, compare the objective function values of candidate solutions generated by various neighborhood structures and find the largest one. If the solution meets the aspiration criterion, update the tabu list and the current optimal solution and proceed to the next iteration. Otherwise, find a solution with a better objective function value that is not recorded in the tabu list, and continue to iterate until the termination condition is met.

5.2.2. N-Shift Search Strategy. The neighborhood search strategy mainly considers the decision variables $x_{j}, y_{i, j, r, t}$. First, select two decision variables $a$ and $b, a=a \pm n(n$ $\in\{1,2,3,0.1 a, 0.2 a, 0.5 a\}), \quad b=b+n(n \in\{1,2,3,0.1 a, 0.2 a$, $0.5 a\}$ ), and then make the obtained solution feasible. Finally, repeat the same operation as $n$-flip for the remaining steps. 


\subsection{Feasible Strategy}

Step 1: check the value of $p_{i, j}$; if $p_{i, j}$ meets constraints (2) and (3), then proceed to Step 2; otherwise, set $p_{i, j}$ as $\left(d_{i, j, r, t}-\varepsilon_{i, j, r,} \quad t+\alpha \cdot q_{j, s}-\gamma \cdot l_{i, j, s} /-\beta\right) \cdot\left(p_{i, j}^{\max }-p_{i, j}^{\min }\right)+$ $p_{i, j}^{\min }$, and then implement Step 2 .

Step 2: check the value of $x_{j}$; if $x_{j}$ meets constraint (6), then proceed to Step 3; otherwise, adjust the magnitude of the neighborhood transform; for example, if performing $n$-flip operation on $x_{j}$, then set $x_{j}=\sum_{i \in I} \sum_{j \in J} d_{i, j, r, t}-\sum_{j_{1} \in J, j_{1} \neq j} x_{j}$ to meet constraint (6).

Step 3: check whether the value of $y_{i, j, r, t}$ satisfies constraints (4) and (5); if not, adjust the magnitude of the neighborhood transform; for example, if performing $n$-flip operation on $y_{i, j, r, t}$, then set $y_{i, j, r, t}=x_{j}-\sum_{i_{1} \in I, i_{1} \neq i} y_{i_{1}, j, r, t}$.

\subsection{Tabu Search Strategy}

(1) Tabu list design: this paper records each solution plan in the tabu list to ensure that the plan cannot be adopted again within the specified tabu length. If the length of the tabu is exceeded, the plan cannot be recorded in the tabu list. Through this strategy, the algorithm can accept relatively inferior solutions, thereby expanding the search area and preventing falling into local optimal solutions.

Metropolis criterion is the most commonly used SA acceptance criterion: if the gap $\Delta E<0$, then update the state; otherwise, accept the new solution as the new current state with probability $e^{-(\Delta E) / T_{i}} ; T_{i}$ is the current temperature.

Since this paper studies the maximization problem, if $\Delta E>0$, introduce the Metropolis criterion; if $\Delta E<0$, accept the new solution with probability $e^{-(\Delta E) / T_{i}}$; otherwise, skip the solution. According to the above rules, in the initial situation, the tabu list has a small influence on the current solution, but as the number of iterations increases, the influence of the tabu list on the current solution gradually increases.

(2) Aspiration criterion: if the accuracy of the new obtained solution defeats the current one, regardless of whether the solution has been recorded in the tabu list, the solution is selected for the next iteration and set to the current optimal solution.

\section{Numerical Experiments}

In order to verify the effectiveness of the proposed model for the operation and management optimization of the medical enterprises based on social responsibility under Industry 5.0, numerical experiments are carried out in this paper. The CPU of the experimental platform used in this paper is Intel Xeon E5-2643 v4 $3.4 \mathrm{GHz}$, the memory is $256 \mathrm{~GB}$, and the 64-bit Windows 10 processing system is adopted. The code is implemented in C\#, and the C\# version is Visual Studio 2015. CPLEX version is 12.6.1.
6.1. The Setting of Experiment. Based on the background of the optimization of medical enterprises' operations management considering social responsibility, according to the 2019 Annual Report of a medical technology enterprise focusing on the development and manufacturing of assisted surgical robot products, the parameters are set as follows (unit: ten thousand $\mathrm{RMB}$ ) $: e_{1,1}=2, e_{1,2}=10, e_{2,1}=$ $10, e_{2,2}=3, v_{1,1}=0, v_{1,2}=0, v_{2,1}=275, v_{2,2}=325, w_{1}=290$, $w_{2}=200 . \theta^{D}$ and $\theta^{K}$ are random numbers between 0 and 1 , respectively. Set the operating cost of the initial stage $c_{1,0}=46, c_{2,0}=84, c_{j, t}$ will be affected by technical learning coefficient $\theta^{K}$, and $c_{j, t+1}=c_{j, t} \cdot \theta^{K}$. In this paper, the parameters $d_{i, j, r, t}$ are determined by random numbers $\varepsilon_{i, j, r, t}$, and the conversion coefficients $\alpha, \beta$, and $\gamma$ are, respectively, related to the ranges of $q_{j}, p_{i, j}$, and $l_{i, j}[33$.

\subsection{Comparative Analysis of CPLEX, IVNTS, VNS, and PSO.} The particle swarm optimization (PSO) algorithm exhibits the advantages of simple operation and fast convergence speed. It seeks an approximate optimal solution by simulating the behavior of bird swarms flying for food [34]. In this paper, VNS and PSO are used as comparative algorithms for analysis.

As shown in Table 2, CPLEX can quickly find the optimal solution of the model under small-scale instances, while the IVNTS, VNS, and PSO algorithms can only find the approximate optimal solution. In Table 1, (1) represents the number of different scenarios, (2) is the example number, (3) and (4), respectively, represent the objective value and running time calculated by CPLEX, (5) and (6) are the value of objective value and running time calculated by the IVNTS, respectively, (7) and (8) represent the objective value and running time calculated by the VNS, respectively, (9) and (10) represent the objective value and running time calculated by the PSO, respectively, and (11)-(13), respectively, represent the gap of objective value between CPLEX and IVNTS, between CPLEX and VNS, and between CPLEX and PSO.

As the scale of the instances increases, the advantages of the IVNTS are gradually manifested. Compared with CPLEX, VNS, and PSO, IVNTS performs well in computing time and solution accuracy. As for computing time, taking in terms of ID $1-13$, the computing time of CPLEX is $2106.95 \mathrm{~s}$, while that of VNS is $74.10 \mathrm{~s}$, and PSO is $5853.52 \mathrm{~s}$. The IVNTS proposed in this paper only needs $31.38 \mathrm{~s}$ to get an approximate optimal solution with a gap of only $0.92 \%$ from the optimal solution. As for solution accuracy, IVNTS can jump out of the local optimum and the average gap of objective function value between CPLEX and IVNTS is only $0.94 \%$. Compared with IVNTS, VNS falls in solution accuracy, which is affected by randomness to a certain extent, and can easily fall into the local optimum. The average gap between CPLEX and VNS is about $4.65 \%$. The solution accuracy of PSO is affected by the initial particle swarm and the number of iterations, which is time consuming, and the solution accuracy is low. The average gap between CPLEX and PSO is up to $14.14 \%$. Therefore, the proposed algorithm IVNTS can obtain a satisfactory solution with higher solution efficiency. 
TABle 2: Experimental results of CPLEX, IVNTS, VNS, and PSO algorithm.

\begin{tabular}{|c|c|c|c|c|c|c|c|c|c|c|c|c|}
\hline \multirow{2}{*}{$\begin{array}{l}\text { No. of } \\
\text { scenarios }\end{array}$} & \multirow[b]{2}{*}{ ID } & \multicolumn{2}{|c|}{ CPLEX } & \multicolumn{2}{|c|}{ IVNTS } & \multicolumn{2}{|c|}{ VNS } & \multicolumn{2}{|c|}{ PSO } & \multirow{3}{*}{$\begin{array}{c}\text { Gap 1 } \\
(\%) \\
((3)-(5)) / \\
(3) \\
(11)\end{array}$} & \multirow{3}{*}{$\begin{array}{c}\text { Gap } 2 \\
(\%) \\
((3)-(7)) / \\
(3) \\
(12)\end{array}$} & \multirow{3}{*}{$\begin{array}{c}\text { Gap } 3 \\
(\%) \\
((3)-(9)) / \\
(3) \\
(13)\end{array}$} \\
\hline & & $F_{\text {CPLEX }}$ & $t_{\text {CPLEX }}(s)$ & $F_{\text {IVNTS }}$ & $t_{\text {IVNTS }}(s)$ & $F_{\mathrm{VNS}}$ & $t_{\mathrm{VNS}}(s)$ & $F_{\mathrm{PSO}}$ & $t_{\mathrm{PSO}}(s)$ & & & \\
\hline (1) & $(2)$ & (3) & (4) & (5) & (6) & (7) & (8) & (9) & (10) & & & \\
\hline \multirow{3}{*}{10} & $1-1$ & 75119473 & 13 & 74312181 & 1 & 72570208 & 2 & 66281431 & 41 & 1.07 & 3.39 & 11.76 \\
\hline & $1-2$ & 12391060 & 1 & 12369708 & 1 & 10936930 & 3 & 10374169 & 36 & 0.17 & 11.73 & 16.27 \\
\hline & $1-3$ & 75386952 & 13 & 74939979 & 1 & 71823927 & 2 & 63768913 & 39 & 0.59 & 4.73 & 15.41 \\
\hline \multirow{3}{*}{20} & $1-4$ & 38174673 & 58 & 37638077 & 2 & 36927580 & 5 & 31717785 & 93 & 1.40 & 3.26 & 16.91 \\
\hline & $1-5$ & 74059300 & 59 & 74015988 & 2 & 71105310 & 5 & 62423441 & 74 & 0.05 & 3.99 & 15.71 \\
\hline & $1-6$ & 74990846 & 53 & 73944770 & 2 & 72289103 & 5 & 65684406 & 99 & 1.39 & 3.60 & 12.41 \\
\hline \multirow{3}{*}{50} & $1-7$ & 72518095 & 138 & 72443244 & 6 & 69381445 & 13 & 63135881 & 413 & 0.10 & 4.32 & 12.93 \\
\hline & $1-8$ & 67798109 & 133 & 66688187 & 5 & 64280139 & 14 & 62790950 & 427 & 1.63 & 5.19 & 7.39 \\
\hline & $1-9$ & 74003531 & 212 & 73906326 & 6 & 71622281 & 12 & 62717069 & 352 & 0.13 & 3.22 & 15.25 \\
\hline \multirow{3}{*}{100} & $\begin{array}{l}1- \\
10\end{array}$ & 34235277 & 1132 & 33897068 & 11 & 32927579 & 26 & 28759932 & 1159 & 0.98 & 3.82 & 15.99 \\
\hline & $\begin{array}{l}1- \\
11\end{array}$ & 31170697 & 1138 & 30466141 & 11 & 29620799 & 26 & 26537846 & 1215 & 2.26 & 4.97 & 14.86 \\
\hline & $\begin{array}{l}1- \\
12\end{array}$ & 25935253 & 1123 & 25914970 & 11 & 25166245 & 24 & 21580964 & 1053 & 0.07 & 2.97 & 16.79 \\
\hline \multirow{3}{*}{300} & $\begin{array}{l}1- \\
13\end{array}$ & 27731962 & 2107 & 27475841 & 31 & 26104859 & 74 & 23017460 & 5854 & 0.92 & 5.87 & 17.00 \\
\hline & $\begin{array}{l}1- \\
14\end{array}$ & 65657602 & 2216 & 64535712 & 34 & 62341335 & 72 & 60571991 & 6210 & 1.70 & 5.05 & 7.75 \\
\hline & $\begin{array}{l}1- \\
15\end{array}$ & 39434250 & 2102 & 38791550 & 30 & 37980630 & 72 & 33259527 & 6151 & 1.62 & 3.69 & 15.66 \\
\hline Avg. & & 52573805 & 700 & 52089316 & 10 & 50338558 & 24 & 45508118 & 1548 & 0.92 & 4.25 & 13.44 \\
\hline
\end{tabular}

TABLE 3: Comparison between IVNTS and VNS in solving large-scale instances.

\begin{tabular}{|c|c|c|c|c|c|c|}
\hline \multirow[b]{2}{*}{$\begin{array}{l}\text { No. of scenarios } \\
\text { (1) }\end{array}$} & \multirow[b]{2}{*}{$\begin{array}{l}\text { ID } \\
(2)\end{array}$} & \multicolumn{2}{|c|}{ IVNTS } & \multicolumn{2}{|c|}{ VNS } & \multirow{2}{*}{$\begin{array}{c}\text { Gap } 4(\%) \\
((3)-(5)) /(3) \\
(7)\end{array}$} \\
\hline & & $\begin{array}{c}F_{\text {IVNTS }} \\
(3)\end{array}$ & $\begin{array}{c}t_{\mathrm{IVNTS}}(s) \\
(4)\end{array}$ & $\begin{array}{c}F_{\mathrm{VNS}} \\
(5)\end{array}$ & $\begin{array}{c}t_{\mathrm{VNS}}(s) \\
(6)\end{array}$ & \\
\hline \multirow{3}{*}{500} & $2-1$ & 54005399 & 56 & 52112121 & 149 & 3.51 \\
\hline & $2-2$ & 71840319 & 56 & 69678547 & 149 & 3.01 \\
\hline & $2-3$ & 96142014 & 55 & 94297413 & 111 & 1.92 \\
\hline \multirow{3}{*}{1000} & $2-4$ & 103445443 & 115 & 100639097 & 241 & 2.71 \\
\hline & $2-5$ & 100261581 & 107 & 96384316 & 217 & 3.87 \\
\hline & $2-6$ & 40878897 & 102 & 39145464 & 241 & 4.24 \\
\hline \multirow{3}{*}{2000} & $2-7$ & 72761376 & 226 & 69709448 & 609 & 4.19 \\
\hline & $2-8$ & 93410532 & 221 & 90413849 & 524 & 3.21 \\
\hline & $2-9$ & 50810559 & 212 & 50010375 & 467 & 1.57 \\
\hline \multirow{3}{*}{5000} & $2-10$ & 94348955 & 555 & 92533744 & 1240 & 1.92 \\
\hline & $2-11$ & 64548958 & 564 & 61881264 & 1330 & 4.13 \\
\hline & $2-12$ & 73732942 & 533 & 72218310 & 1148 & 2.05 \\
\hline Avg. & & 76348915 & 234 & 74085329 & 536 & 2.96 \\
\hline
\end{tabular}

6.3. Comparative Analysis of IVNTS and VNS Algorithms. Since CPLEX cannot used for solution in medium- and large-scale experimental scenarios, this paper compares the IVNTS algorithm with the initial VNS. Considering the long running time and low accuracy, PSO performs poorly in small-scale instances; thus PSO will not be compared and analyzed in medium- and large-scale instances. From Table 3, as the scale increases, IVNTS performs better than VNS in both computing time and solution accuracy, which shows that the algorithm proposed in this paper is effective for solving the original model.

\subsection{Sensitivity Analysis}

6.4.1. Analysis of the Demand Learning Coefficient $\theta^{D}$. Figure 4 shows the impact of the demand learning coefficient $\theta^{D}$ on the CSR of domestic and foreign suppliers. The 


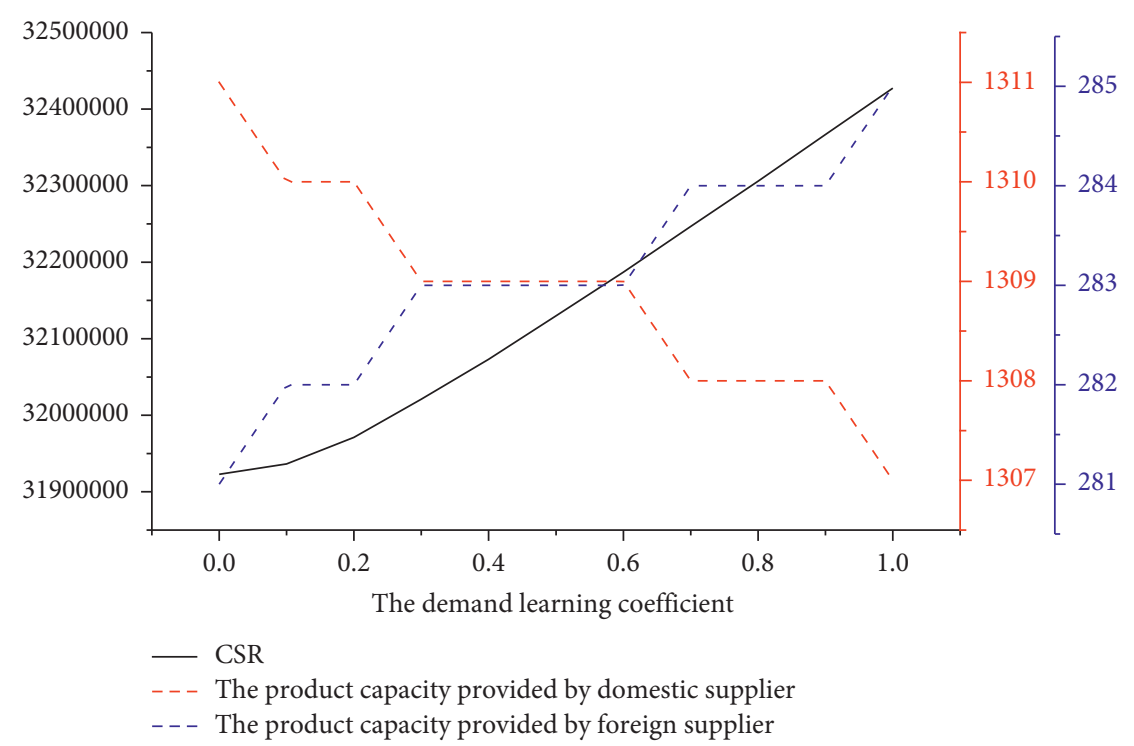

Figure 4: Analysis of the demand learning coefficient $\theta^{D}$.

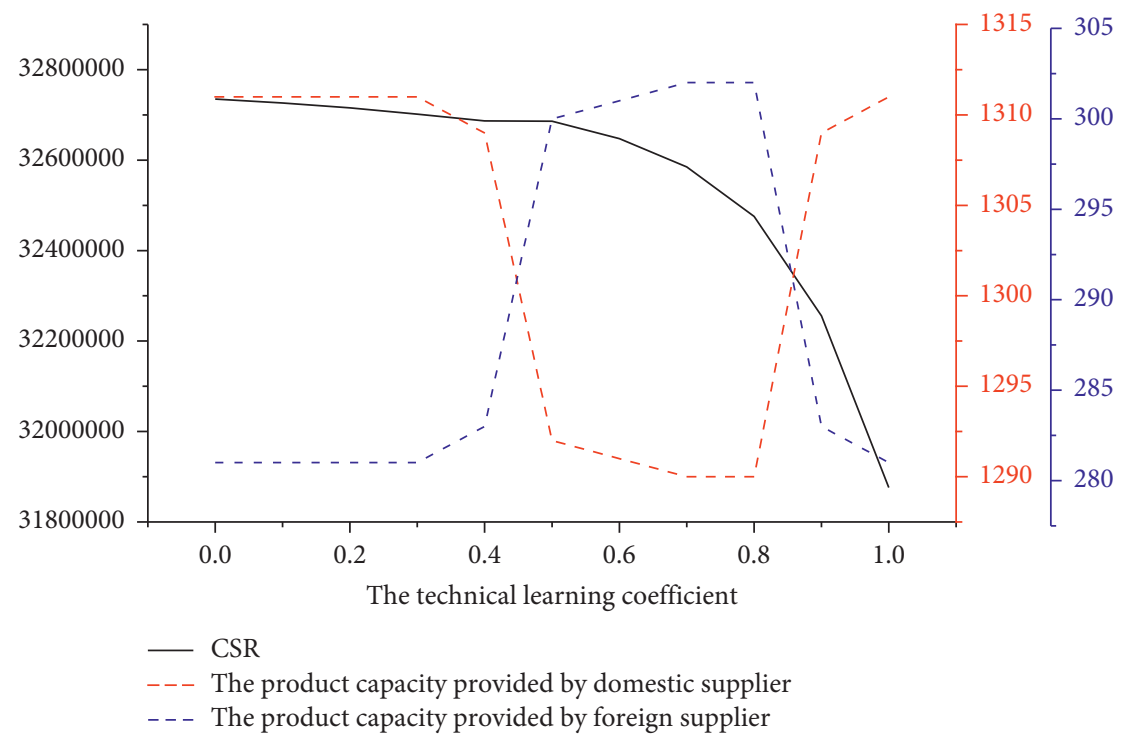

Figure 5: Analysis of the technical learning coefficient $\theta^{K}$.

demand learning coefficient is a positive indicator, which affects the product demand $d_{i, j, r, t}$. It can be seen from the figure that, with the improvement of demand learning, CSR is gradually increasing. While the total domestic and foreign production capacity remains steady, the production capacity of domestic suppliers shows a stepwise increase, while the production capacity of foreign suppliers shows a stepwise decrease.

6.4.2. Analysis of the Technical Learning Coefficient $\theta^{K}$. Figure 5 shows the impact of technical learning coefficient $\theta^{K}$ on the CSR of domestic and foreign suppliers. The technical learning coefficient is a negative indicator, and $\theta^{K}$ affects the unit operating $\operatorname{cost} c_{j t}$. The smaller the value of $\theta^{K}$, the more advanced the technology and the lower the cost. It can be seen from the figure that as the technical learning coefficient increases (the technology is more backward), the CSR gradually decreases, while the production capacity of domestic and foreign suppliers fluctuates. When $\theta^{K} \in[0,0.3] \cup[0.5,0.8], x_{j}$ tends to be stable. When $\theta^{K} \in(0.3,0.5) \cup(0.8,1), x_{j}$ changes sharply.

6.4.3. Analysis of Product Profit Rate. Figure 6 shows the impact of product profit rate on the CSR of domestic and foreign suppliers. The profit margin reflects the initial profitability of the company's product sales. The product profit margin is calculated as follows: Product profit margin = product price operating cost/ operating cost $\times 100 \%$. Figure 5 shows that when the product profit margin is lower than $90 \%$, as the product profit margin increases, the CSR will also increase. 


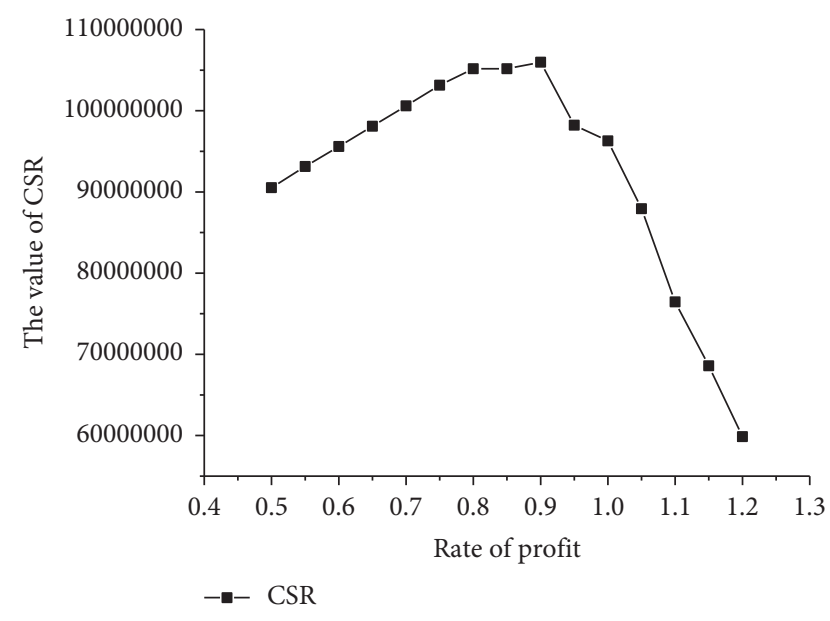

FIgURE 6: Analysis of product profit margin.

TABle 4: Abbreviations list.

\begin{tabular}{lc}
\hline Abbreviation & Full name \\
\hline CSR & Corporate social responsibility \\
MIP & Mixed-integer programming \\
SRs & Surgical robots \\
VNS & Variable neighborhood search \\
VNTS & Variable neighborhood tabu search \\
IVNTS & Improved variable neighborhood tabu search \\
SA & Simulated annealing \\
Industry 5.0 & The fifth industrial revolution \\
AI & Artificial intelligence \\
TS & Tabu Search \\
PSO & Particle swarm optimization \\
\hline
\end{tabular}

However, when the product profit margin is higher than $90 \%$, the high product price will affect the market demand, leading to a downward trend in CSR.

\section{Conclusions}

This paper studies the optimization of the medical enterprises' operations management considering social responsibility under Industry 5.0. This problem combines the global supply chain sales and operation network, with the goal of maximizing the social responsibility of medical enterprises, and an MIP model is constructed, which determines the product prices, the production capacity, and the quantity of actual supply. This paper designs an IVNTS algorithm combining with the Metropolis of the SA algorithm and aspiration criteria, which can generate the satisfactory solution in a short time. In order to verify the effectiveness of the algorithm, a large number of numerical experiments have been carried out in this paper. The experimental results show that, compared with CPLEX, the IVNTS algorithm performs well in computing time and is able to solve large-scale instances. As for the comparison with other heuristic algorithms, the algorithm proposed in this paper performs well in solution accuracy, which can jump out of the local optimal and obtain the satisfactory solution, and the average deviation with the optimal solution is only $0.94 \%$.
Based on the experimental results, this article draws the following management implications:

(1) The sales market's product demand is affected by the degree of demand learning $\theta^{D}$, and the product demand determines the actual supply of the supplier. With the increase of $\theta^{D}$, the CSR gradually increases. When there is a scale effect, the average cost of CSR will be reduced, and the increase in demand will bring certain profits to the company; thus the CSR will become greater.

(2) The social responsibilities of domestic and foreign medical enterprises are influenced by the technological learning coefficient $\theta^{K}$. As $\theta^{K}$ increases (the degree of technology is more backward), the CSR gradually declines. Therefore, enterprises should promptly introduce new technology, thereby reducing corporate operating costs while improving CSR, which will bring much more customer needs due to the increasing customer satisfaction.

(3) The product profit margin is determined by the product price and unit operating cost. When the product profit margin is lower than $90 \%$, the CSR becomes greater as the product profit margin increases, but when the product profit margin is higher than $90 \%$, CSR shows a downward trend with the increase in product profit margins. Excessive product prices will affect the market demand. From the perspective of corporate sustainable development, it is recommended that companies, on the one hand, appropriately reduce profit margins and effectively reduce operating costs through the utilization of emerging technologies and, on the other hand, reduce product prices to stimulate market demand, which is conducive to the realization of long-term stable and sustainable development of the enterprise.

Future research can further discuss the impact of government policies and regulations [35], closed-loop supply chain network design [36], green port optimization [37], and Internet-of-things and other difficult-to-quantify features on CSR and corporate sustainable development. The study of providing decision support should be strengthened by constructing a complete CSR evaluation index and standardization system.

Table 4 lists the abbreviations of technical terms used in this study.

\section{Data Availability}

The data used to support the findings of this study are included within the article.

\section{Disclosure}

Yuming Chen was added as a co-first author. 


\section{Conflicts of Interest}

The authors declare that they have no conflicts of interest.

\section{Authors' Contributions}

Qian Zhang and Yuming Chen contributed equally to this work. Qian Zhang was responsible for the writing of the original version of the manuscript, as well as the development of mathematical models and algorithm. Yuming Chen was responsible for the writing of the revised manuscript and improving the language and logical structure. Wanlong Lin was responsible for the running of experiment and the sensitivity analysis. Yao Chen was responsible for the topic selection and original ideas of the study, and she also provided the parameter values used in this study.

\section{References}

[1] L. He, M. Xue, and B. Gu, "Internet-of-things enabled supply chain planning and coordination with big data services: certain theoretic implications," Journal of Management Science and Engineering, vol. 5, no. 1, pp. 1-22, 2020.

[2] Z. Sarfraz, A. Sarfraz, H. M. Iftikar, and R. Akhund, "Is COVID-19 pushing us to the fifth industrial revolution (society 5.0)?" Pakistan Journal of Medical Sciences, vol. 37, no. 2, pp. 591-594, 2021.

[3] A. P. Barbosa-Póvoa, C. da Silva, and A. Carvalho, "Opportunities and challenges in sustainable supply chain: an operations research perspective," European Journal of Operational Research, vol. 268, no. 2, pp. 399-431, 2018.

[4] V. Özdemir and N. Hekim, "Birth of industry 5.0: making sense of big data with artificial intelligence, "the internet of things" and next-generation technology policy," OMICS: A Journal of Integrative Biology, vol. 22, no. 1, pp. 65-76, 2018.

[5] J. J. Sung, C. L. Stewart, and B. Freedman, "Artificial intelligence in health care: preparing for the fifth industrial revolution," Medical Journal of Australia, vol. 213, no. 6, pp. 253-255, 2020.

[6] M. Mehmood, "Heart failure with preserved ejection fraction, the fifth industrial revolution and humanity," Journal of the American College of Cardiology: Heart Failure, vol. 8, no. 2, pp. 155-156, 2020.

[7] S. Rai and A. Rai, "Review: nanotechnology - the secret of fifth industrial revolution and the future of next generation," Nusantara Bioscience, vol. 7, no. 2, pp. 61-66, 2015.

[8] P. Sachsenmeier, "Industry 5.0-the relevance and implications of bionics and synthetic biology," Engineering, vol. 2, no. 2, pp. 225-229, 2016.

[9] S. Nahavandi, "Industry 5.0-A human-centric solution," Sustainability, vol. 11, no. 16, p. 4371, 2019.

[10] L. Chen, L. Zhang, J. Huang, H. Xiao, and Z. Zhou, "Social responsibility portfolio optimization incorporating ESG criteria," Journal of Management Science and Engineering, vol. 6, no. 1, pp. 75-85, 2021.

[11] A. Manikas, L. Boyd, J. Guan, and K. Hoskins, "A review of operations management literature: a data-driven approach," International Journal of Production Research, vol. 5, no. 58, pp. 1442-1461, 2020.

[12] Y. Feng, Q. Zhu, and K.-H. Lai, "Corporate social responsibility for supply chain management: a literature review and bibliometric analysis," Journal of Cleaner Production, vol. 158, pp. 296-307, 2017.
[13] B. Afsar, B. M. Al-Ghazali, Z. U. Rehman, and W. A. Umrani, "Retracted: the moderating effects of employee corporate social responsibility motive attributions (substantive and symbolic) between corporate social responsibility perceptions and voluntary pro-environmental behavior," Corporate Social Responsibility and Environmental Management, vol. 27, no. 2, pp. 769-785, 2020.

[14] K. Mark, "Creating shared value: how to reinvent capitalism and unleash a wave of innovation and growth," Harvard Business Review, vol. 89, no. 1-2, pp. 62-77, 2011.

[15] Q. Zhu and K.-h. Lai, "Enhancing supply chain operations with extended corporate social responsibility practices by multinational enterprises: social capital perspective from Chinese suppliers," International Journal of Production Economics, vol. 213, pp. 1-12, 2019.

[16] J. E. Koo and E. S. Ki, "Corporate social responsibility and employee safety: evidence from Korea," Sustainability, vol. 12, no. 7, p. 2649, 2020.

[17] E. C. Kurucz, B. A. Colbert, and D. Wheeler, "The business case for corporate social responsibility," in The Oxford Handbook of Corporate Social ResponsibilityOxford, UKOUP Oxford, 2008.

[18] T. F. Babor and K. Robaina, "Public health, academic medicine, and the alcohol industry's corporate social responsibility activities," American Journal of Public Health, vol. 103, no. 2, pp. 206-214, 2013.

[19] G. Daú, A. Scavarda, L. F. Scavarda, and V. J. T. Portugal, “The healthcare sustainable supply chain 4.0: the circular economy transition conceptual framework with the corporate social responsibility mirror," Sustainability, vol. 11, no. 12, p. 3259, 2019.

[20] H. L. Lee and C. S. Tang, "Socially and environmentally responsible value chain innovations: new operations management research opportunities," Management Science, vol. 64, no. 3, pp. 983-996, 2018.

[21] E. W. T. Ngai, C. C. H. Law, C. W. H. Lo, J. K. L. Poon, and S. Peng, "Business sustainability and corporate social responsibility: case studies of three gas operators in China," International Journal of Production Research, vol. 56, no. 1-2, pp. 660-676, 2018.

[22] J. M. Cruz and D. Matsypura, "Supply chain networks with corporate social responsibility through integrated environmental decision-making," International Journal of Production Research, vol. 47, no. 3, pp. 621-648, 2009.

[23] J. M. Cruz, "Mitigating global supply chain risks through corporate social responsibility," International Journal of Production Research, vol. 51, no. 13, pp. 3995-4010, 2013.

[24] J.-Y. Liu, "An internal control system that includes corporate social responsibility for social sustainability in the new era," Sustainability, vol. 10, no. 10, p. 3382, 2018.

[25] L. Zhen, "A three-stage optimization model for production and outsourcing under China's export-oriented tax policies," Transportation Research Part E: Logistics and Transportation Review, vol. 69, pp. 1-20, 2014.

[26] L. Huang, L. Zhen, and L. Yin, "Waste material recycling and exchanging decisions for industrial symbiosis network optimization," Journal of Cleaner Production, vol. 276, Article ID 124073, 2020.

[27] P. Hansen and N. Mladenović, "Variable neighborhood search: principles and applications," European Journal of Operational Research, vol. 130, no. 3, pp. 449-467, 2001.

[28] P. Hansen, N. Mladenović, and J. A. Moreno Pérez, "Variable neighbourhood search: methods and applications," Annals of Operations Research, vol. 175, no. 1, pp. 367-407, 2010. 
[29] H. Li, M. Bai, Y. Zhao, and C. Dai, "Vehicle flow formulation for two-echelon time-constrained vehicle routing problem," Journal of Management Science and Engineering, vol. 4, no. 2, pp. 75-90, 2019.

[30] M. Qiu, Z. Fu, R. Eglese, and Q. Tang, “A Tabu search algorithm for the vehicle routing problem with discrete split deliveries and pickups," Computers \& Operations Research, vol. 100, pp. 102-116, 2018.

[31] D. Schermer, M. Moeini, and O. Wendt, "A hybrid VNS/Tabu search algorithm for solving the vehicle routing problem with drones and en route operations," Computers \& Operations Research, vol. 109, pp. 134-158, 2019.

[32] P. Koken, H. Seok, and S. W. Yoon, "A simulated annealing algorithm with neighbourhood list for capacitated dynamic lot-sizing problem with returns and hybrid products," International Journal of Computer Integrated Manufacturing, vol. 31, no. 8, pp. 739-747, 2018.

[33] Z. Zhiyan, "Research on surgical robot industry," 2021, https://36kr.com/p/864269635902344.

[34] L. Zhen, Z. Xu, C. Ma, and L. Xiao, "Hybrid electric vehicle routing problem with mode selection," International Journal of Production Research, vol. 58, no. 2, pp. 562-576, Article ID 1598593, 2019.

[35] L. Huang, Y. Xu, X. Pan, and T. Zhang, "Green technology collaboration network analysis of China's transportation sector: a patent-based analysis," Scientific Programming, vol. 202112 pages, Article ID 9961071, 2021.

[36] L. Zhen, L. Huang, and W. Wang, "Green and sustainable closed-loop supply chain network design under uncertainty," Journal of Cleaner Production, vol. 227, pp. 1195-1209, 2019.

[37] L. Zhen, Z. Liang, D. Zhuge, L. H. Lee, and E. P. Chew, "Daily berth planning in a tidal port with channel flow control," Transportation Research Part B: Methodological, vol. 106, pp. 193-217, 2017. 